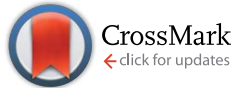

Cite this: Chem. Sci., 2015, 6, 3225

\title{
Is a polymer semiconductor having a "perfect" regular structure desirable for organic thin film transistors? $\uparrow$
}

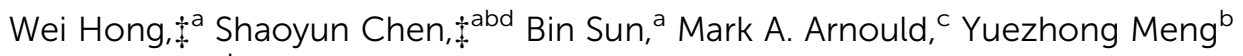 \\ and Yuning $\mathrm{Li}^{\star a}$
}

This study utilized high temperature NMR and matrix-assisted laser desorption/ionization time-of-flight (MALDI-ToF) mass spectrometry to reveal that appreciable amounts of structural defects are present in the diketopyrrolopyrrole (DPP)-quaterthiophene copolymers (PDQT) synthesized by the Stille coupling polymerization with $\mathrm{Pd}\left(\mathrm{PPh}_{3}\right)_{2} \mathrm{Cl}_{2}, \mathrm{Pd}_{2}(\mathrm{dba})_{3} / \mathrm{P}(\mathrm{o}-\text {-tol })_{3}$, and $\mathrm{Pd}\left(\mathrm{PPh}_{3}\right)_{4}$ catalyst systems. It was proposed that these structural defects were produced via homocoupling side reactions of the $\mathrm{C}-\mathrm{Br}$ bonds and the organostannane species. Model Stille coupling reactions further substantiated that the amount of structural defects are catalyst-dependent following the order of $\mathrm{Pd}\left(\mathrm{PPh}_{3}\right)_{2} \mathrm{Cl}_{2}>\mathrm{Pd}_{2}(\mathrm{dba})_{3} / \mathrm{P}(\mathrm{o} \text {-tol })_{3}>$ $\mathrm{Pd}\left(\mathrm{PPh}_{3}\right)_{4}$. To verify the structural assignments, "perfect" structurally regular PDQT polymers were prepared using Yamamoto coupling polymerization. When compared to the structurally regular polymers, the polymers containing defects exhibited notable redshifts in their absorption spectra. Surprisingly, the "perfect" structurally regular polymers showed poor molecular ordering in thin films and very low charge transport performance as channel semiconductors in organic thin film transistors (OTFTs). On the contrary, all the "defected" polymers exhibited much improved molecular ordering and significantly higher charge carrier mobility.

Received 9th March 2015

Accepted 28th March 2015

DOI: $10.1039 /$ c5sc00843c

www.rsc.org/chemicalscience known example of this behavior is poly(3-hexylthiophene) (P3HT). The regio-irregular P3HT forms amorphous films that exhibit low charge carrier mobility $\left(\sim 10^{-5} \mathrm{~cm}^{2} \mathrm{~V}^{-1} \mathrm{~s}^{-1}\right),{ }^{17}$ but the highly regio-regular, head-to-tail P3HT is crystalline and has demonstrated significantly improved mobility (up to $\sim 0.1 \mathrm{~cm}^{2}$ $\left.\mathrm{V}^{-1} \mathrm{~s}^{-1}\right)^{5,18}$ in OTFTs. Very few random copolymers have been reported for OTFTs ${ }^{19,20}$ since the molecular ordering of random copolymers would be hindered, resulting in lower mobility compared to the regular alternating copolymers. ${ }^{19}$

In recent years, polymer semiconductors having alternating electron donor (D) and acceptor (A) units on their backbone have received escalating attention due to their remarkable performance as channel semiconductors in OTFTs. ${ }^{21-26}$ Charge carrier mobility as high as $\sim 10 \mathrm{~cm}^{2} \mathrm{~V}^{-1} \mathrm{~s}^{-1}$ has recently been achieved. ${ }^{27-30}$ The excellent charge transport performance observed for these $\mathrm{D}-\mathrm{A}$ polymers is believed to be brought about by the strong intermolecular D-A interaction that could shorten the co-facial $\pi-\pi$ stacking distance between conjugated polymer main chains allowing for more efficient charge hopping. ${ }^{23}$ One of the most commonly used synthetic approaches to D-A polymers is the Stille coupling reaction, ${ }^{31,32}$ where an organoditin (or organodistannane) and an organodielectrophile (often a dihalo compound) are used as comonomers in the presence of a Pd catalyst to form a long chain polymer.

Previously we reported a D-A polymer, PDQT (Scheme 1) ) $^{33-35}$ having a diketopyrrolopyrrole (DPP) and a quaterthiophene in 
the repeat unit, which showed high hole mobility up to $6.9 \mathrm{~cm}^{2}$ $\mathrm{V}^{-1} \mathrm{~s}^{-1}$ in OTFTs. Initially this polymer (P1) was synthesized using the Stille coupling reaction of 3,6-bis(5-bromothiophen-2yl)-2,5-bis(2-octyldodecyl)pyrrolo[3,4-c]pyrrole-1,4(2H,5H)-dione (M1a) and 5,5'-bis(trimethylstannyl)-2,2'-bithiophene with $\mathrm{Pd}\left(\mathrm{PPh}_{3}\right) \mathrm{Cl}_{2}$ as a catalyst. ${ }^{33}$ In subsequent studies, we also used another catalyst system consisting of $\mathrm{Pd}_{2}(\mathrm{dba})_{3} / \mathrm{P}(o \text {-tol })_{3}(\mathbf{P} 2)$ in order to increase the molecular weight of the polymer to improve mobility. ${ }^{27}$ Interestingly, we noticed that the PDQT polymers synthesized with these two different catalyst systems showed dramatically different UV-Vis absorption spectra in both solution and the solid state. This suggests that they may have different backbone structures and that at least one of these two catalysts resulted in structural defects, prompting us to investigate their structural differences in more detail. The Suzuki coupling reaction ${ }^{36}$ is another frequently used crosscoupling polymerization technique for synthesizing conjugated polymers. A recent paper by Janssen and coworkers ${ }^{37}$ reported that homocoupling side reactions of the bromo compounds were observed in the Suzuki coupling reaction with a catalyst system $\mathrm{Pd}_{2}(\mathrm{dba})_{3} / \mathrm{PPh}_{3}$ (with a molar ratio of $1: 1$ ). The presence of these structural defects had a detrimental effect on the photovoltaic performance of the polymers and should be avoided. The authors also suggested that the Stille coupling reaction with the same catalyst system might involve similar side reactions.

In this study, we investigated the structures and properties of PDQT polymers synthesized by the Stille coupling polymerization using three common catalyst systems: $\mathrm{Pd}\left(\mathrm{PPh}_{3}\right) \mathrm{Cl}_{2}$,
$\mathrm{Pd}_{2}(\mathrm{dba})_{3} / \mathrm{P}(o \text {-tol })_{3}$, and $\mathrm{Pd}\left(\mathrm{PPh}_{3}\right)_{4}$. Our results unambiguously demonstrate that significant amounts of structural defects were produced during the Stille coupling polymerization. It was found that these structural defects have significant impacts on the UV-Vis absorption, molecular ordering, as well as the OTFT performance of these polymers.

\section{Results and discussion}

PDQT polymers P1, P2a, and P3 were synthesized by the Stille coupling polymerization of the dibromo monomer M1a with equivalent $\quad 5,5^{\prime}$-bis(trimethylstannyl)-2,2'-bithiophene using three different $\mathrm{Pd}$ catalyst systems, $\mathrm{Pd}\left(\mathrm{PPh}_{3}\right)_{2} \mathrm{Cl}_{2}, \mathrm{Pd}_{2}(\mathrm{dba})_{3} / \mathrm{P}(o$ tol $)_{3}$ (molar ratio: $\left.1 / 4\right)$, and $\mathrm{Pd}\left(\mathrm{PPh}_{3}\right)_{4}$, as outlined in scheme 1 . Polymer P4a was prepared by the Yamamoto coupling polymerization $^{38}$ of the dichloro monomer M2a using $\mathrm{Ni}(\mathrm{COD})_{2}$. Each repeat unit in P4a has one DBT and two thiophenes ( $\mathrm{T}-$ DBT-T), which is equivalent to the repeat unit (DBT-BT) of P1, P2a, and P3 (Scheme 1). However, P4a can be considered a homopolymer and only one type of repeat unit would exist in the resulting polymer. A branched long chain hydrocarbon, 2-octyldodecyl (C20), was used on the DPP unit to improve the solubility of the polymers. P1, P2a, and P3 made via the Stille coupling showed good solubility in chloroform, while P4a made by the Yamamoto coupling is insoluble in the same solvent. A soluble fraction of P4a (34\%) was obtained by Soxhlet extraction with 1,1,2,2-tetrachloroethane (TCE), which has a much higher boiling point $\left(146.5{ }^{\circ} \mathrm{C}\right)$ than chloroform $\left(61.2{ }^{\circ} \mathrm{C}\right)$. The extremely poor solubility of $\mathbf{P 4 a}$ is thought to be due to the
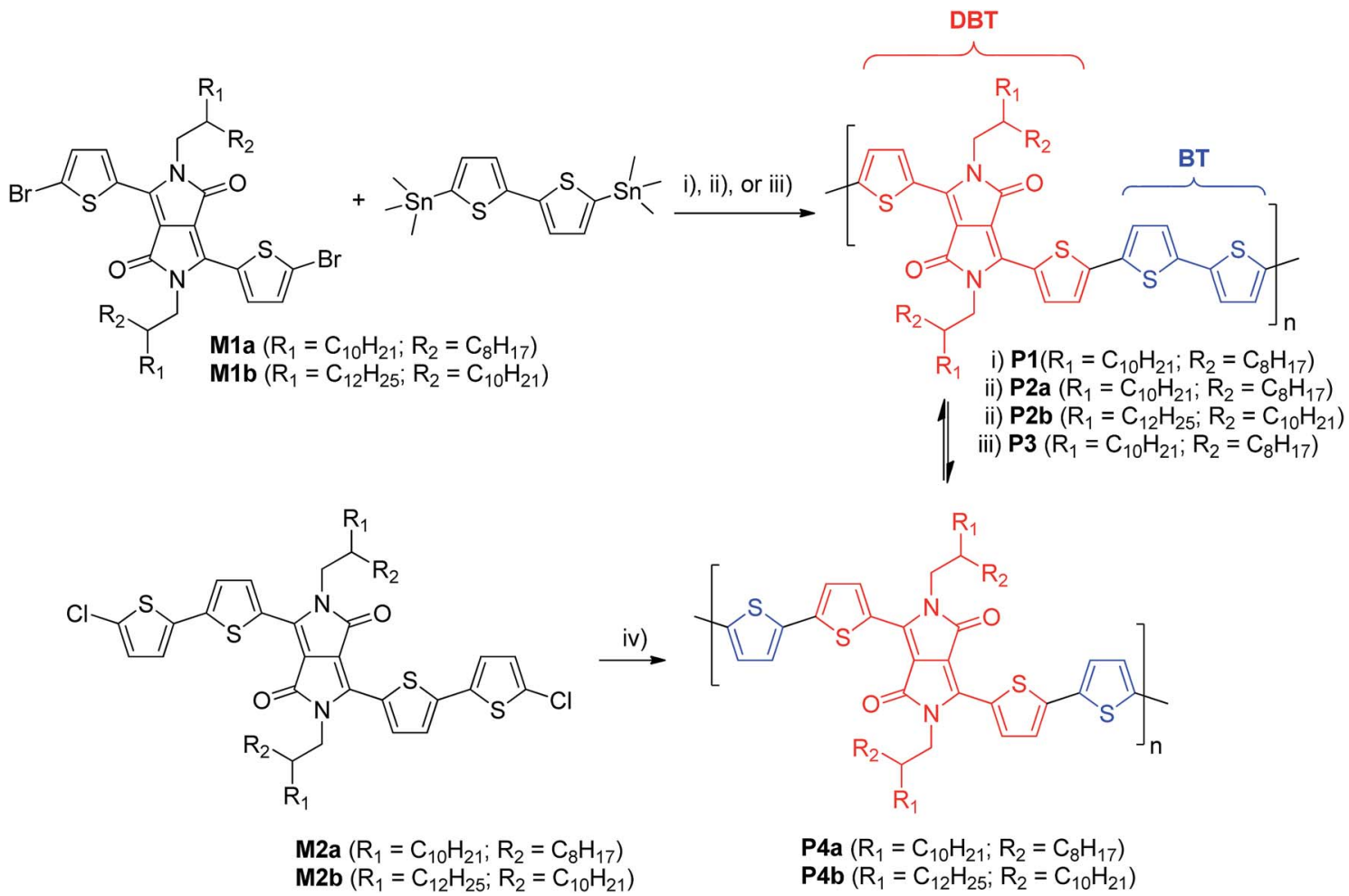

Scheme 1 Synthetic routes to PDQT polymers P1-P4: (i) $\mathrm{Pd}\left(\mathrm{PPh}_{3}\right)_{2} \mathrm{Cl}_{2} /$ toluene/reflux; (ii) $\mathrm{Pd}_{2}(\mathrm{dba})_{3} / \mathrm{P}(\mathrm{o}$-tol) 3 (molar ratio: $1 / 4) / c h l o r o b e n z e n e /$ $130{ }^{\circ} \mathrm{C}$; (iii) $\mathrm{Pd}\left(\mathrm{PPh}_{3}\right)_{4} /$ toluene/reflux; (iv) $\mathrm{Ni}(\mathrm{COD})_{2} / 2,2^{\prime}$ - bipyridyl/THF $/ 60{ }^{\circ} \mathrm{C}$. 
Table 1 Summary of molecular weights and properties of polymers $\mathrm{P} 1-\mathrm{P} 4^{a}$

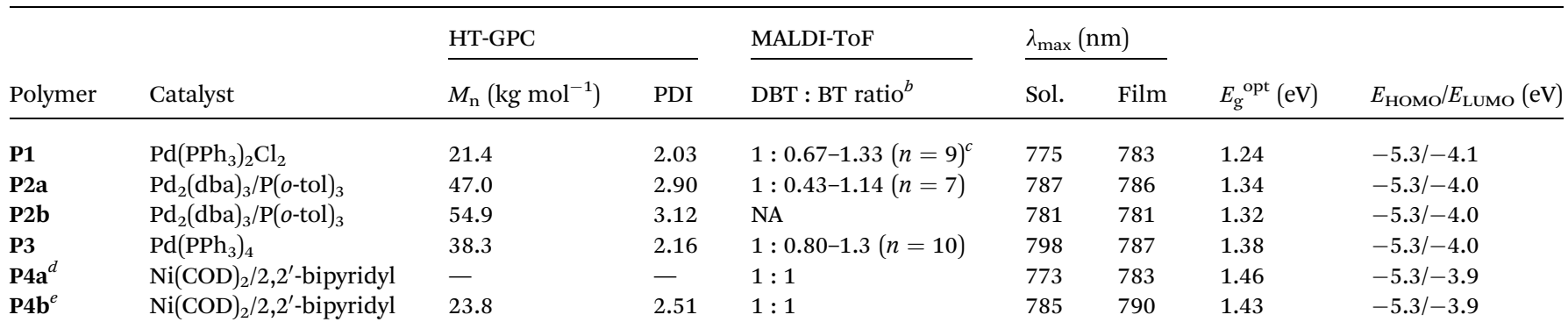

${ }^{a}$ HT-GPC, UV-Vis, and cyclic voltammetry data for P2a and P2b were reported previously. ${ }^{34,35}{ }^{b}$ DBT: 3,6 -di([2,2'-bithiophen]-5-yl)-2,5-bis(2octyldodecyl)pyrrolo[3,4-c]pyrrole-1,4(2H,5H)-dione or 3,6-di([2,2'-bithiophen]-5-yl)-2,5-bis(2-tetradecyldecyl)pyrrolo[3,4-c]pyrrole-1,4(2H,5H)-dione, BT: $2,2^{\prime}$-bithiophen-diyl. ${ }^{c} n$ : the number of DBT units. ${ }^{d}$ The fraction extracted with TCE. ${ }^{e}$ The fraction extracted with chloroform.

highly regular structure of the polymer yielding an extremely rigid backbone. To improve the solubility, a longer side chain, 2-decyltetradecyl (C24), was used and the resulting polymer P4b exhibited much better solubility $(62.1 \%$ and $24.8 \%$ yields were obtained from the fractions extracted with chloroform and TCE, respectively; only the fraction extracted with chloroform was used for characterization of this polymer in this study). In order to make a direct comparison with P4b, P2b with the same C24 side chain was prepared using the $\mathrm{Pd}_{2}(\mathrm{dba})_{3} / \mathrm{P}(o \text {-tol })_{3}$ catalyst.

The molecular weight of these polymers was measured using a high temperature gel-permeation chromatography (HT-GPC) system at $140{ }^{\circ} \mathrm{C}$ with 1,2,4-trichlorobenzene as an eluent and polystyrene as standards. The results are summarized in Table 1. All the polymers have the number average molecular weight $\left(M_{\mathrm{n}}\right)$ greater than $20 \mathrm{~kg} \mathrm{~mol}^{-1}$. Due to the poor solubility of $\mathbf{P 4 a}$, its molecular weight could not be measured with this method.

The UV-Vis spectra of the polymers are shown in Fig. 1. In solution, the polymers showed the wavelengths of maximum absorption $\left(\lambda_{\max }\right)$ ranging from $773 \mathrm{~nm}$ to $798 \mathrm{~nm}$. The relatively small $\lambda_{\max }(773 \mathrm{~nm}$ ) observed for P4a is thought to be due to the lower molecular weight of its soluble fraction in TCE. Most of the polymers showed a slight redshift $(<10 \mathrm{~nm})$ in $\lambda_{\max }$ for the thin film when compared with the solution spectra due to intermolecular interaction in the solid state. It was also observed that these polymers showed dramatic differences in the long wavelength absorption side of the spectra (particularly in thin films) due to the presence of homocoupled defects in the polymer backbone. ${ }^{37}$ (This phenomenon will be further discussed later.) P1 displayed the most pronounced extension into the long wavelength region, followed by $\mathbf{P 2}$ then P3, with P4 showing the least. Therefore the optical band gaps for these polymers follow a trend of P4 $>$ P3 $>$ P2 $>$ P1. The molecular weight of the polymers, which correlates to the main chain conjugation length, would influence the band gap of the polymers if the maximum effective conjugation length is not reached. However, the differences in the molecular weight do not seem to correlate with the different absorption profiles observed for these polymers synthesized using different catalyst systems. For instance, it can be seen that P1, with the lowest molecular weight among these polymers (except for P4a), showed the largest redshift. Therefore, the main reason for the redshifts observed for P1-P3 as compared to $\mathbf{P 4}$ might be due to their potentially different backbone structures. The highest occupied molecular orbital (HOMO) energy levels of these polymers are very similar $(\sim-5.3 \mathrm{eV})$ as determined by cyclic voltammetry with ferrocene as a reference (Table 1). The lowest unoccupied molecular orbital (LUMO) energy levels were estimated using the $E_{\text {Номо }}$ and the optical band gaps to be around $-4 \mathrm{eV}$ with the highest value of $-3.9 \mathrm{eV}$ for $\mathbf{P 4 a}$ and $\mathbf{P 4 b}$ and the lowest value of $-4.1 \mathrm{eV}$ for $\mathbf{P 1}$.

${ }^{1} \mathrm{H}$ NMR was utilized to investigate the molecular structures of these polymers. However ${ }^{1} \mathrm{H}$ NMR spectra of all the polymers measured at room temperature in $\mathrm{CDCl}_{3}$ or deuterated 1,1,2,2-
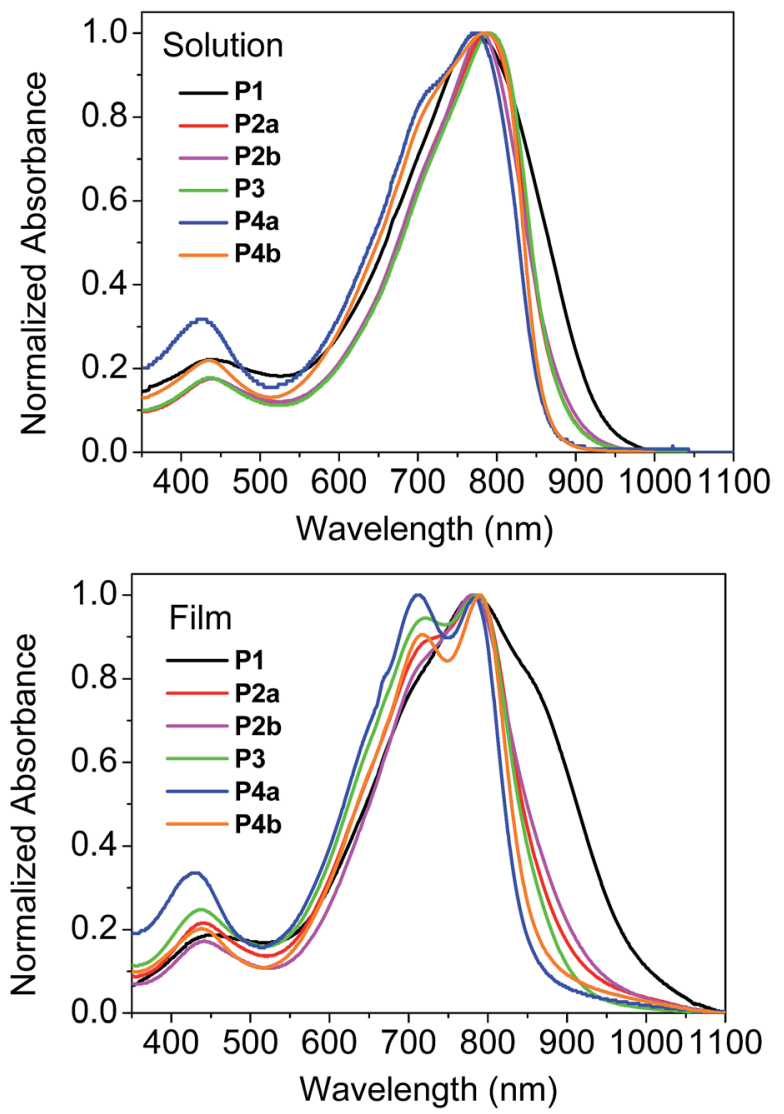

Fig. 1 UV-Vis absorption spectra of P1-P4 in solution (TCE) and in thin films. 


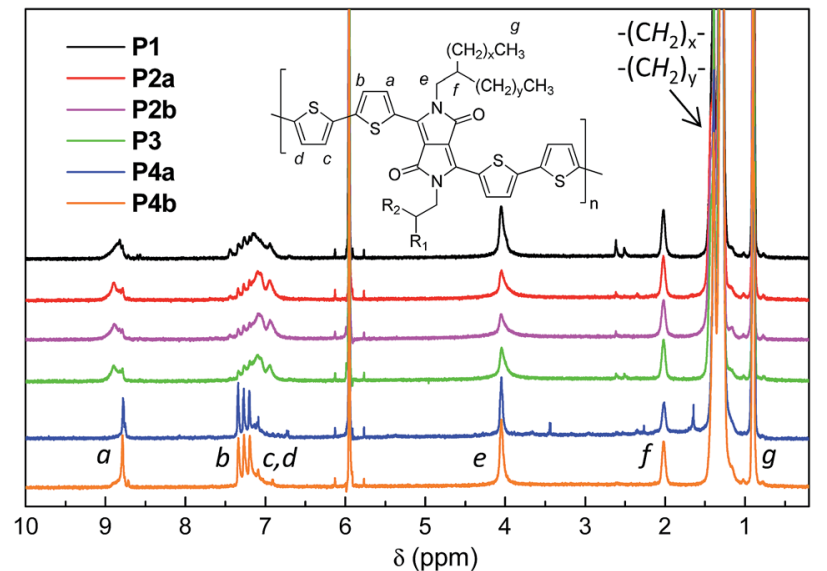

Fig. $2500 \mathrm{MHz}{ }^{1} \mathrm{H}$ NMR spectra of P1-P4 acquired in deuterated 1,1,2,2-tetrachloroethane $\left(\mathrm{TCE}-\mathrm{d}_{2}\right)$ at $125^{\circ} \mathrm{C}$.

tetrachloroethane (TCE- $\mathrm{d}_{2}$ ) showed very broad peaks (ESI $\dagger$ ), indicating that the polymer chains aggregated in solution, a phenomenon that has been observed for some other D-A polymers. ${ }^{33,39}$ The resolution of the ${ }^{1} \mathrm{H}$ NMR spectra was improved by measuring the polymers in TCE- $\mathrm{d}_{2}$ at an elevated temperature of $125{ }^{\circ} \mathrm{C}$ to dissociate the polymer chain aggregates. This resulted in well-resolved peaks for the spectra of P4a and P4b (Fig. 2). As expected, these two polymers showed quite simple resonance peak patterns due to the presence of the exact repeat units enabled by the Yamamoto coupling polymerization. Some minor peaks are also observed and can be assigned to the end groups. Distinct peaks in the aromatic region for P1-P3, which correspond to those in P4, are observed, but several intense peaks at other positions are also present. The observation of more complex NMR patterns for P1-P3 compared to $\mathbf{P 4}$ is most likely due to their different backbone structures. This strongly suggests that side reactions occurred to form structural defects during the Stille coupling polymerization with the catalyst systems utilized in this study.

To shed more light on the polymer structures, MALDI-ToF mass spectroscopy was utilized to obtain the molecular masses for individual polymer chains after GPC separation. Fig. 3 shows that for P4a and $\mathbf{P 4 b}$ there is an excellent agreement of the measured molecular masses of the polymers with the calculated/theoretical values (represented by the vertical dashed lines), indicating their perfect polymer structures with exact repeat units. The offset from the theoretical values arises from the masses of the end groups. On the other hand, the molecular masses of $\mathbf{P 1}$ are mostly not observed at the theoretical molecular masses, but appear to be distributed more like a random copolymer yielding a distribution of distributions, i.e., there exist many chains containing less or more BT units than expected. There are dominant end group structures, so the spectrum is not further convoluted by overlapping end group distributions. In the spectrum of P2a, the distributions are more severely affected due to the extremely complex distribution of end group structures (with similar intensities) superimposed onto the broad comonomer distribution. The mass spectrum of $\mathbf{P 3}$ shows a better overall match to the theoretical values as compared to P1 and P2a. The broad comonomer distribution for each of the P1, P2a and P3 samples as compared to $\mathbf{P 4 a}$ and $\mathbf{P 4 b}$ indicates that there are significant amounts of structural defects in these polymers. For example, the ratio of the two comonomer units (DBT and BT) for P1 were calculated for polymer chains containing 9 DBT units $(n=9)$. It was found that these peaks correspond to molecules having DBT : BT ratios of $9: 6-12$ (1:0.67-1.33) (Table 1). The existence of polymer chains with DBT : BT ratios greater than the expected largest possible ratio of $1: 0.89$ for polymers with alternating DBT and BT units (DBT $:$ BT $=9: 8,9: 9$, and $9: 10$ (or $1: 0.89,1: 1$, and 1.11)) suggests that some DBT units are adjoined or homocoupled. For P2a, polymer chains around $n=7$ have DBT : BT ratios between $1: 0.43$ and $1: 1.14$, indicating that there exist chains having larger than the DBT : BT ratios expected for molecules with alternating DBT : BT units $(7: 6,7: 7$, and $7: 8$ (or $1: 0.86,1: 1$, and $1: 1.14)$ ). Again, this indicates that this polymer has many DBT-DBT homocoupling units. The DBT : BT ratios of $\mathbf{P} 3$ molecules around $n=10$ are in the range of $10: 8-13(1: 0.8-1.3)$, which are close to the expected ratios of $10: 9,10: 10$, and $10: 11(1: 0.9,1: 1$, and $1: 1.1)$, suggesting that this polymer has less homocoupling DBT-DBT units. Polymers $\mathbf{4 a}$ and $\mathbf{4 b}$ showed an exact DBT : BT ratio of $1: 1$ for all the peaks since their monomers have an intrinsic DBT : BT ratio of $1: 1$.

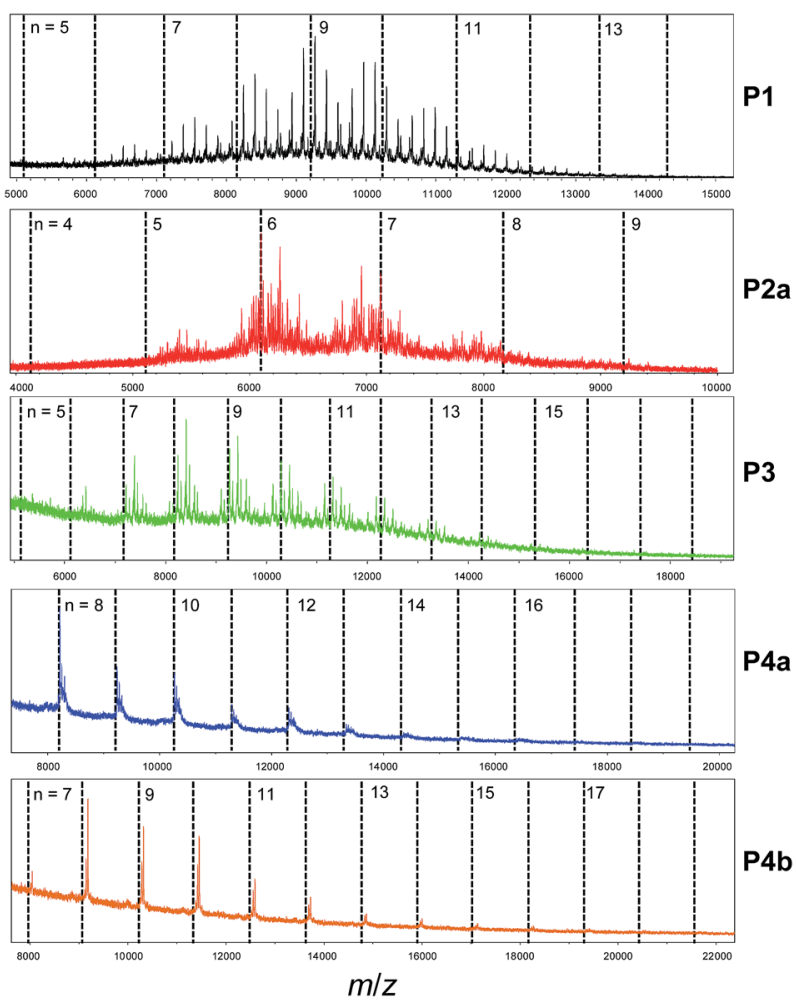

Fig. 3 MALDI-ToF mass spectra of polymers from selected times in the chromatograms, where the vertical dashed lines represent the theoretical molecular masses of polymers with the regular structure - $(\mathrm{DBT}-\mathrm{BT})_{n}-$ at different numbers of repeat units $(n)$ without contribution of the terminal groups. 
To further investigate the possible side reactions during the Stille coupling, model reactions between M1a and a monostannyl compound, 2-trimethylstannylthiophene, were conducted using the three catalyst systems under the same reaction conditions for synthesizing P1, P2a, and P3, respectively (Scheme 2a). The expected product 1a was isolated from the final reaction mixtures by column chromatography on silica gel with yields of $62.1 \%, 83.0 \%$, and $89.9 \%$ with respect to the individual reaction conditions (i), (ii), and (iii) used for P1, P2a, and P3, respectively. A by-product 2a was isolated for all three model reactions. A surprisingly large amount of $\mathbf{2 a}(32.9 \%$ isolated yield) was obtained when $\mathrm{Pd}\left(\mathrm{PPh}_{3}\right) \mathrm{Cl}_{2}$ was used as the catalyst, while $10.6 \%$ (ii) and $5.6 \%$ (iii) of compound $2 \mathrm{a}$ were isolated for reactions using $\mathrm{Pd}_{2}(\mathrm{dba})_{3} / \mathrm{P}(o \text {-tol })_{3}$ and $\mathrm{Pd}\left(\mathrm{PPh}_{3}\right)_{4}$, respectively. Compound $2 \mathrm{a}$ was most likely formed from the homocoupling of two C-Br bonds of two M1a molecules and/or the intermediate with one side capped with a thiophene, T-DBT-Br. Based on the yields of the homocoupling product $2 \mathrm{a}$ for the three catalyst systems, it is reasonable to assume that the same type of side reactions involving $\mathrm{C}-\mathrm{Br}$ containing species occurred during the Stille coupling polymerization (Scheme $2 \mathrm{~b}$ ). The content of the DBT-DBT homocoupling defects in the polymers would follow the order of P1 $>$ P2 $>$ P3, which is in agreement with the MALDI-ToF results discussed previously. Similar side reactions were reported very recently for the Suzuki coupling reaction and was also suggested to occur during the Stille coupling polymerization in a different catalyst system
$\mathrm{Pd}_{2}(\mathrm{dba})_{3} / \mathrm{PPh}_{3}(1: 1) \cdot{ }^{37} \mathrm{~A}$ homopolymer of M1a (PDBT-20), which contains only DBT units, was observed to have a much longer $\lambda_{\max }(917 \mathrm{~nm} \text { in solution and } 928 \mathrm{~nm} \text { in thin films })^{40}$ than that of P4, suggesting that the higher the amount of the DBTDBT homocoupling defects, the longer the absorption wavelength of the PDQT polymer. The absorption redshift trend of P1 $>$ P2 > P3 with respect to P4 agrees well with the DBT-DBT defect contents of these polymers. The presence of the largest amount of DBT-DBT defects in P1 also leads to its deepest LUMO energy level among the polymers studied because of the strong electron-accepting effect of the DPP units. It should be noted that other side reactions such as the homocoupling of organostannanes, which is a common side reaction observed for the Stille coupling, ${ }^{41}$ might also occur during the polymerization reactions in this study. This type of side reaction would form the BT-BT homocoupling defects in P1-P3 as illustrated in Scheme $2 \mathrm{~b}$. This could explain the presence of polymer chains that have DBT : BT ratios smaller than expected (with more BT units than expected) for $\mathbf{P 1}$ and $\mathbf{P 3}$ revealed by their MALDI-ToF spectra (Table 1 and Fig. 3). P2a showed the smallest DBT : BT ratio $1: 1.14(7: 8)$ at $n=7$, indicating that less $\mathrm{BT}: \mathrm{BT}$ defects present in this polymer, although the existence of the BT : BT defects in this polymer cannot be completely ruled out solely based on its DBT : BT ratios. Attempts to isolate the possible bithiophene by-product from the model Stille coupling reaction mixtures with column chromatography or detect this byproduct by mass spectroscopy were unsuccessful due to the

a) Model reactions

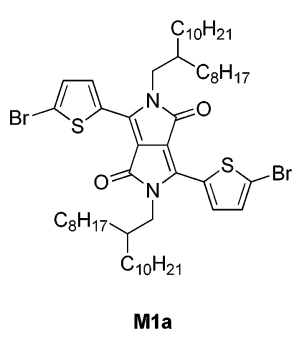

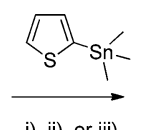

i), ii), or iii)<smiles>C1CCCCC1</smiles>
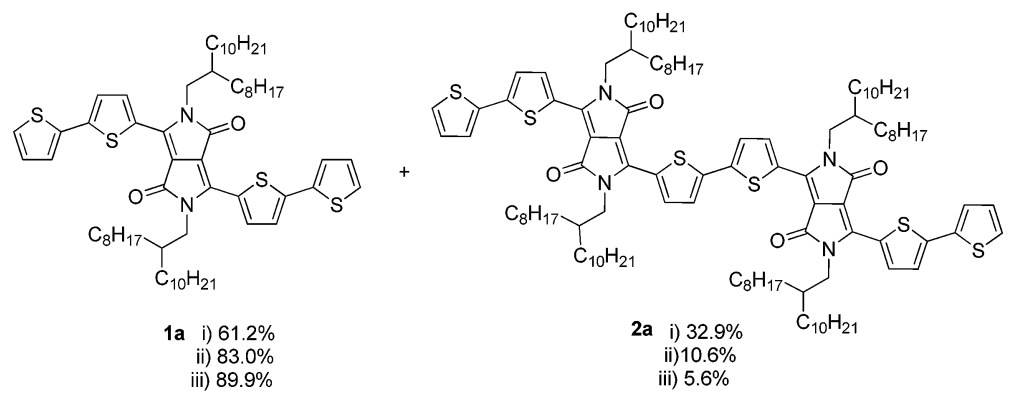

b) Proposed formation of structural defects in P1-P3<smiles></smiles>

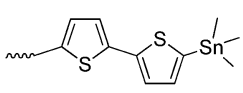<smiles></smiles>

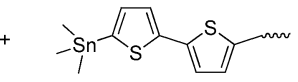

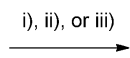
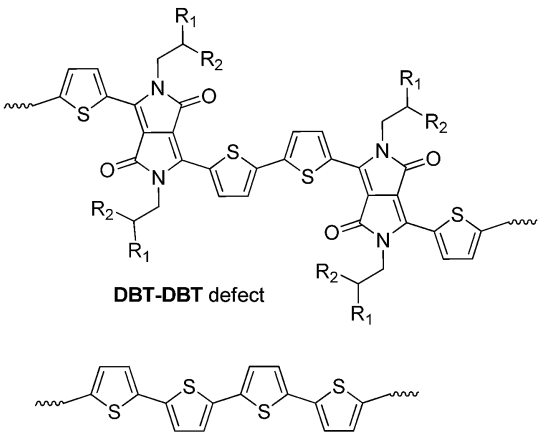

BT-BT defect

Scheme 2 (a) Model Stille coupling reactions using different catalyst systems: (i) $\mathrm{Pd}\left(\mathrm{PPh}_{3}\right)_{2} \mathrm{Cl}_{2} /$ toluene/reflux; (ii) $\mathrm{Pd} \mathrm{d}_{2}(\mathrm{dba})_{3} / \mathrm{P}\left(\mathrm{o}\right.$-tol) ${ }_{3}$ (molar ratio: 1/4)/chlorobenzene $/ 130{ }^{\circ} \mathrm{C}$; (iii) $\mathrm{Pd}\left(\mathrm{PPh}_{3}\right)_{4}$ /toluene/reflux. (b) Proposed formation of structural defects DBT-DBT and BT-BT via the homocoupling side reactions. 

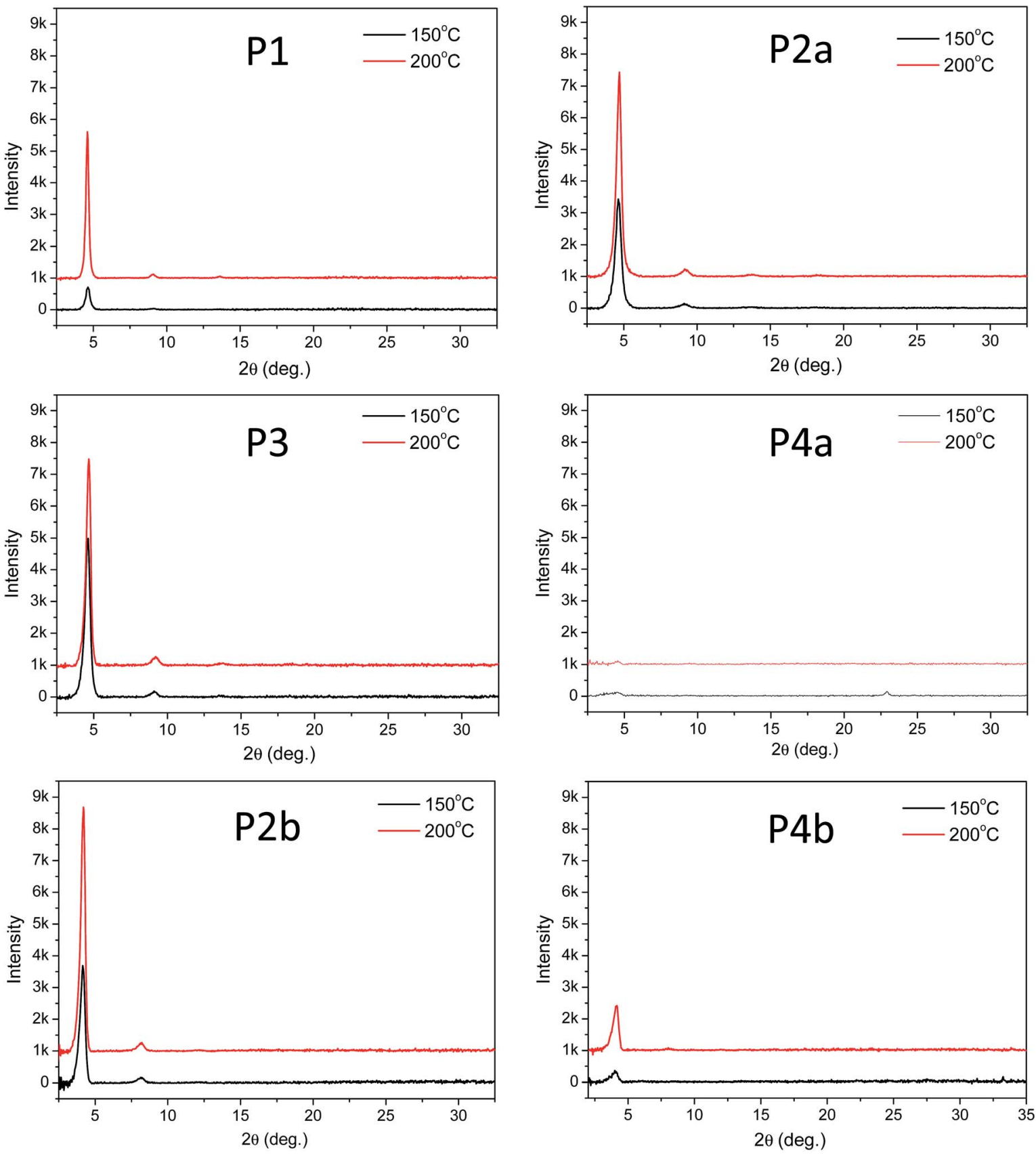

Fig. 4 Reflective XRD diagrams of P1-P4 thin films (with similar thicknesses of $\sim 50 \mathrm{~nm}$ ) spin coated on dodecyltrichlorosilane-modified SiO $2 / \mathrm{Si}$ wafer and annealed at $150^{\circ} \mathrm{C}$ or $200^{\circ} \mathrm{C}$ using Cu Ka1 radiation $(\lambda=0.15406 \mathrm{~nm}$ ). Note that the intensity scale for P4a is one-tenth of that in other diagrams due to the low diffraction intensities of this polymer. Data for P2a and P2b were reported previously. ${ }^{35}$

extremely low anticipated mass yields of this by-product and the interference of other impurities. Nonetheless, the almost quantitative isolated yields of P1-P3 (97-99\%) support that most of the BT units in the 5,5'-bis(trimethylstannyl)-2,2'bithiophene monomer were incorporated into these polymers, which suggests that similarly significant amounts of homocouling BT-BT defects with respect to that of the DBT-DBT defects might be formed.

The above results revealed that $\mathbf{P 4 a}$ and $\mathbf{P 4 b}$ have a regular backbone structure with exact repeat units, while all the polymers (P1-P3) synthesized via the Stille coupling polymerization contain significant amounts of structural defects. Among the Pd catalyst systems used, $\operatorname{Pd}\left(\mathrm{PPh}_{3}\right)_{4}$ afforded the most regular backbone architecture observed in $\mathbf{P 3}$, while $\mathrm{Pd}\left(\mathrm{PPh}_{3}\right)_{2} \mathrm{Cl}_{2}$ produced the most irregular polymer backbone in P1. One would intuitively expect that the molecular ordering of these polymers in the solid state would follow the order of P4 $>$ P3 $>$ P2 $>$ P1 based on their structural regularity. We investigated the chain packing of these polymers in spin-coated thin films using X-ray diffractometry (XRD). As shown in Fig. 4, P1-P3 films are highly crystalline with prominent primary (100) and secondary (200) diffraction peaks that represent the typical layer-by-layer 


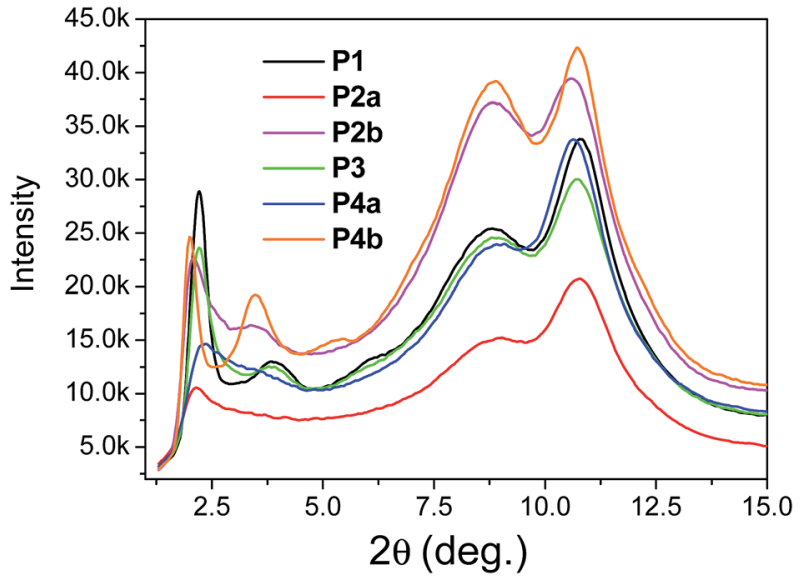

Fig. 5 Transmission XRD diagrams of P1-P4 flakes (thicknesses were not intentionally controlled) annealed at $200^{\circ} \mathrm{C}$ using Mo $\mathrm{K} \alpha$ radiation $(\lambda=0.071073 \mathrm{~nm})$. Data for P2a and P2b were reported previously. ${ }^{35}$ lamellar polymer chain packing. ${ }^{5}$ The absence of the (010) peak that represents the $\pi-\pi$ stacking distance (at $2 \theta=\sim 20-25^{\circ}$ ) indicates that the polymer chains adopted an edge-on orientation. ${ }^{5}$ As anticipated, the crystallinity of the P1-P3 films follows the same order of P3 $>$ P2a $>$ P1 (having the same C20 side chains) as that of their structural regularity, judging from the intensities of their diffraction peaks. Much to our surprise, the structurally regular polymer P4a showed extremely low diffraction intensities, suggesting the very low crystallinity of this polymer. P4b, which has C24 side chains, also showed much poorer molecular ordering compared to $\mathbf{P 2 b}$ that has the same C24 side chains. The reason for the unexpected poor crystallinity of P4a and P4b is not fully understood at this time and needs to be further investigated. We suspect that the regular backbone structure of these two polymers would result in a high degree of rigidity for the polymer main chain, hampering the packing of the polymer molecules. On the other hand, the structural defects present in P1-P3 would provide a desirable flexibility to the polymer backbone, allowing for a slower

Table 2 Summary of XRD results and OTFT performance of polymers P1-P4

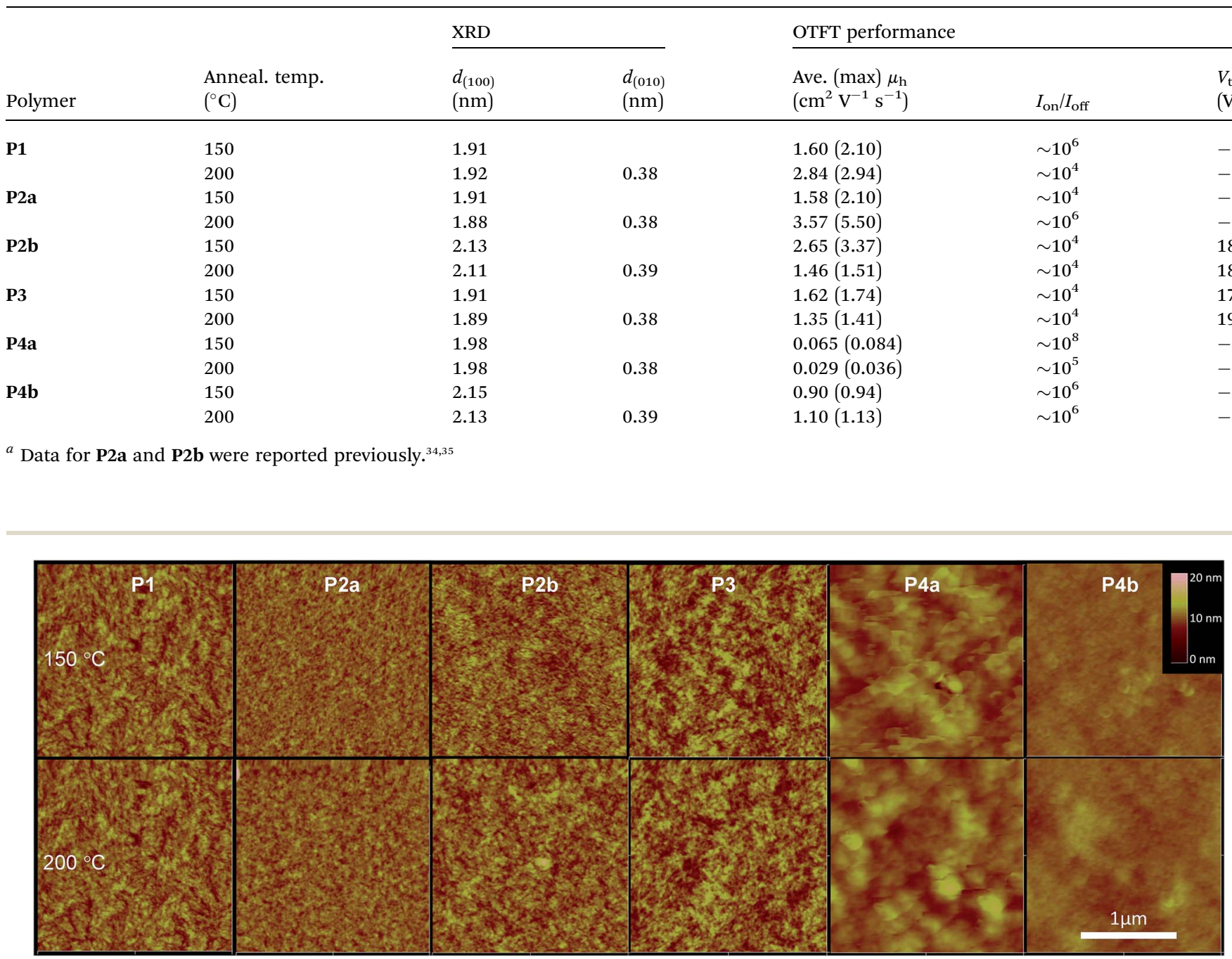

Fig. 6 AFM height images ( $2 \mu \mathrm{m} \times 2 \mu \mathrm{m}$ each) of P1-P4 thin films $(\sim 50 \mathrm{~nm})$ spin-coated on dodecyltrichlorosilane-modified $\mathrm{Si} / \mathrm{SiO} \mathrm{O}_{2}$ wafers and annealed at $150{ }^{\circ} \mathrm{C}$ or $200^{\circ} \mathrm{C}$. Images of P2b were reported previously..$^{35}$ 
P1

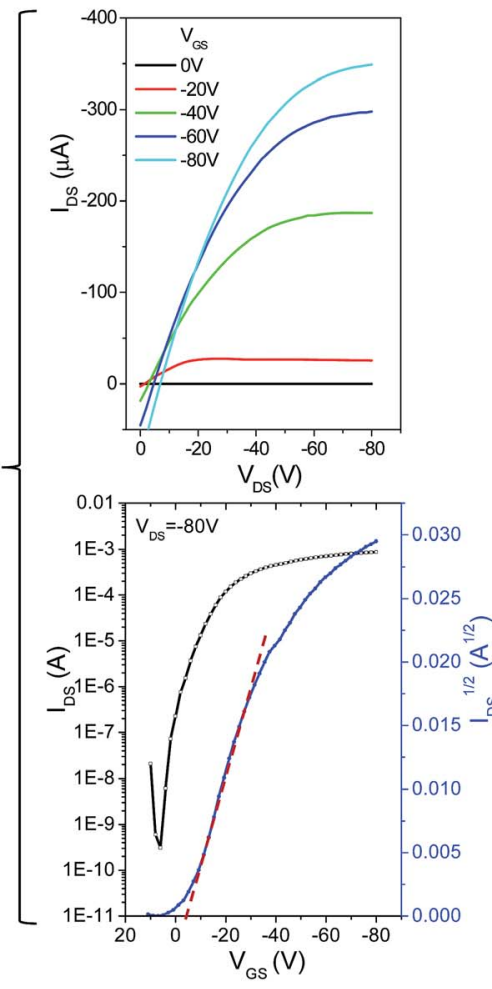

P3

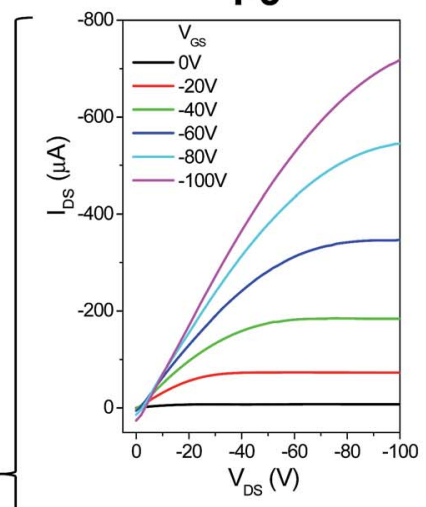

P2a
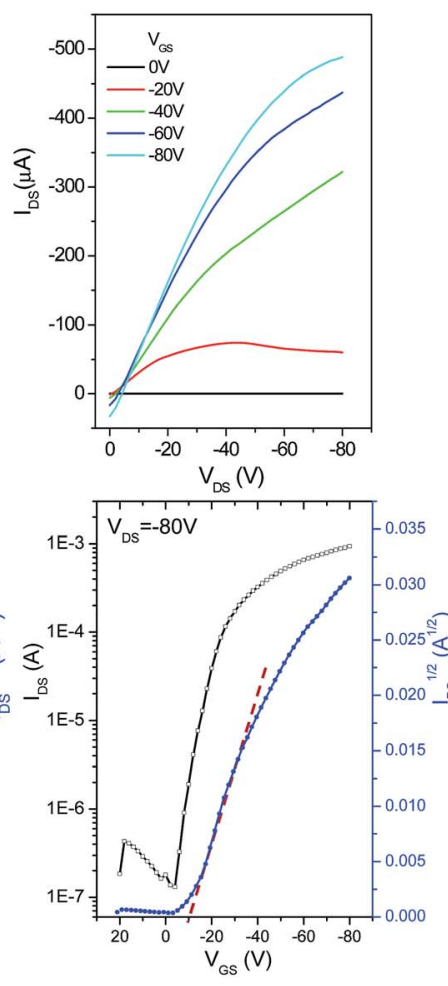

P4a
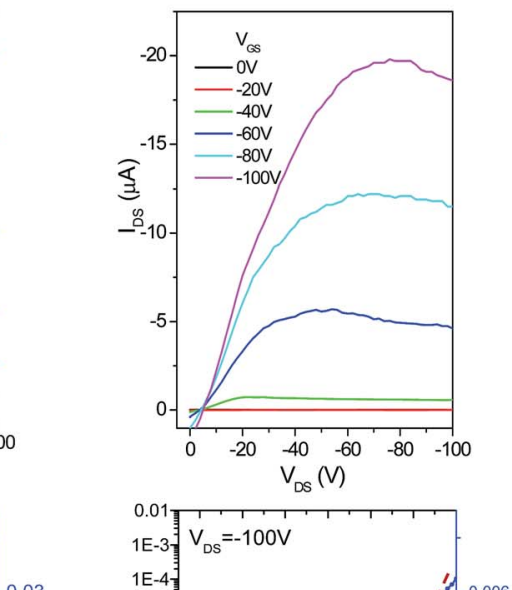
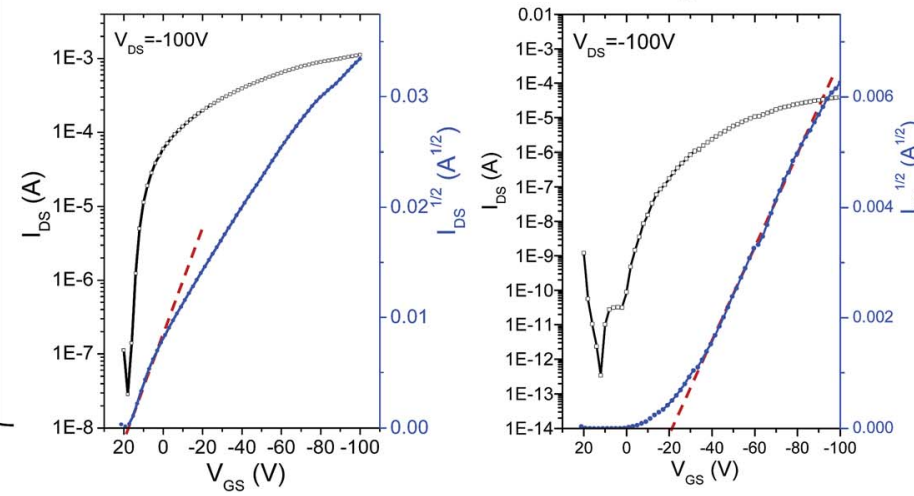

P2b
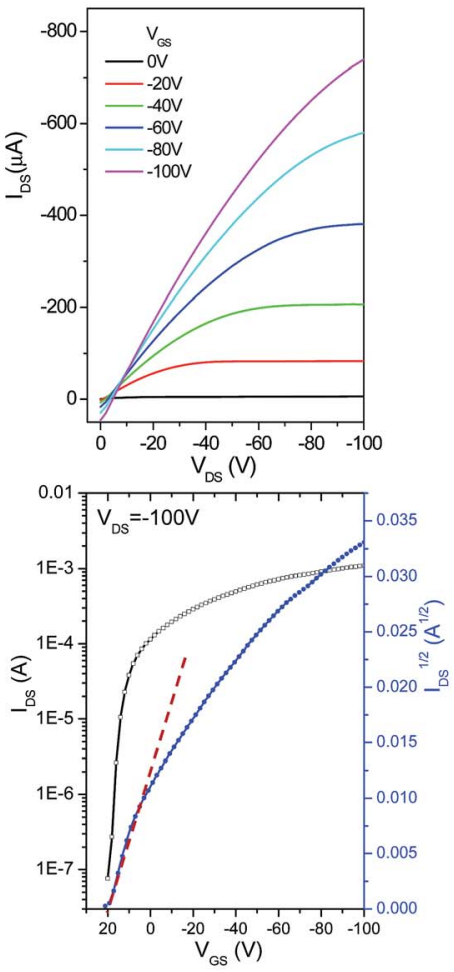

P4b
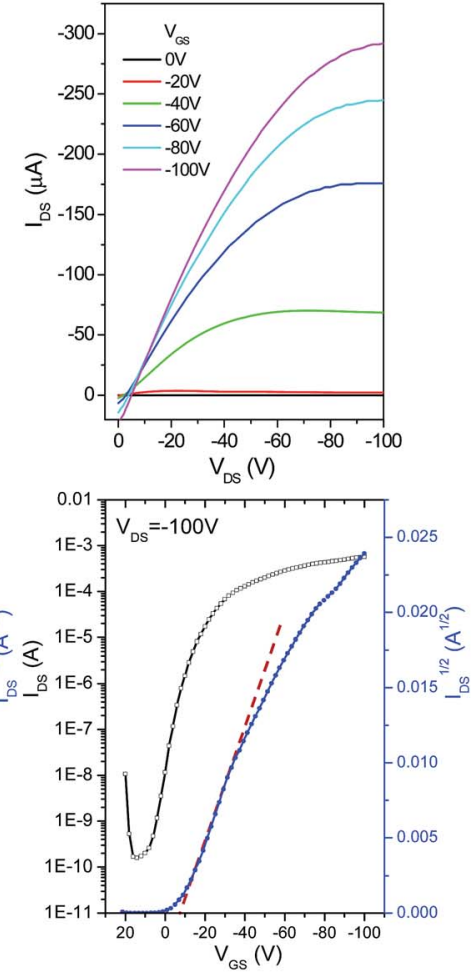

Fig. 7 Output (top) and transfer (bottom) characteristics of typical bottom-gate bottom-contact OTFT devices using polymers P1-P4 as channel semiconductors. The polymer thin films were annealed at $150{ }^{\circ} \mathrm{C}$ for $15 \mathrm{~min}$. Device dimensions: $L=30 \mu \mathrm{m} ; \mathrm{W}=1 \mathrm{~mm}$. N-doped Si/SiO $\mathrm{Z}_{2}$ wafers were used as substrates. The thickness of the dielectric $\mathrm{SiO}_{2}$ layer is $200 \mathrm{~nm}$ for P1 and P2a and $300 \mathrm{~nm}$ for the other polymers. Curves for $\mathrm{P} 2 \mathrm{a}$ and $\mathrm{P} 2 \mathrm{~b}$ were reported previously. ${ }^{35}$ 
crystallization process and a fine tuning of the chain packing. Transmission XRD measurements were conducted on polymer flakes to determine the $\pi-\pi$ stacking distance between polymer backbones (Fig. 5). All polymers showed distinct (010) reflection peaks around $2 \theta=10.6-10.8^{\circ}$, which correspond to $\pi-\pi$ stacking distances of $0.38-0.39 \mathrm{~nm}$ (Table 2). These results suggest that the existence of the structural defects in P1-P3 did not alter the $\pi-\pi$ stacking distance noticeably and would probably not markedly influence the hopping of charge carriers along the $\pi-\pi$ stacks.

The crystallinity of these polymers was also studied by differential scanning calorimetry (DSC) (data are presented in the $\mathrm{ESI}_{\dagger} \dagger$ ). The DSC results showed that for all the polymers having the C20 side chains (P1, P2a, P3, and P4a) only P1 showed a melting point at $287{ }^{\circ} \mathrm{C}$ in the testing temperature range from $-20{ }^{\circ} \mathrm{C}$ to $325^{\circ} \mathrm{C}$. P2a and P3 may have melting points higher than their decomposition temperatures, while P4a probably does not have an obvious melting point based on its poor crystallinity determined by the thin film XRD. For P2b and P4b, which have C24 side chains, P2b showed a distinct melting point at $293{ }^{\circ} \mathrm{C}$, while there was no thermal transition observed for $\mathbf{P 4 \mathbf { b }}$. The melting point of $\mathbf{P 4 \mathbf { b }}$ may also be above its thermal decomposition temperature. Obviously, the existence of structural defects could lower the melting points of the polymers as observed in $\mathbf{P 1}$ and $\mathbf{P 2 b}$. The structural defects might have helped the creep of the polymer chains in achieving more ordered chain packing.

Interconnections of grains in polymer thin films are crucial for charge transport in polymer semiconductors. The atomic force microscopy (AFM) images of polymers P1, P2, and P3 exhibited similar surface morphologies composed of well-connected small grains (Fig. 6). The P2a and P2b films are very smooth followed by an increase in roughness for P1. P3 has the roughest surface among the four polymers synthesized by the Stille coupling polymerization. P4a and P4b showed dramatically different morphologies compared with P1-P3. P4a films showed a very rough morphology comprising of large flakes $\sim 100 \mathrm{~nm}$ in size with the films of $\mathbf{P 4 b}$ being quite smooth composed of small donut-shaped structures.

The charge transport performance of these polymers was evaluated in bottom-gate bottom-contact OTFT devices fabricated on heavily n-doped $\mathrm{Si} / \mathrm{SiO}_{2}$ wafers, where the $\mathrm{Si}$ layer was used as the gate electrode, the $\mathrm{SiO}_{2}$ layer as the dielectric, and gold pairs as source and drain electrodes. Output and transfer curves of typical OTFT devices are provided in Fig. 7. It can be seen in Table 2 that the $150{ }^{\circ} \mathrm{C}$-annealed thin films of P1, P2a, and P3 with the same C20 side chains showed very similar hole mobilities with average values of $\sim 1.6 \mathrm{~cm}^{2} \mathrm{~V}^{-1} \mathrm{~s}^{-1}$. When the polymer films were annealed at $200{ }^{\circ} \mathrm{C}$, the average mobility for $\mathbf{P 1}$ and P2a increased to $2.84 \mathrm{~cm}^{2} \mathrm{~V}^{-1} \mathrm{~s}^{-1}$ and $3.57 \mathrm{~cm}^{2} \mathrm{~V}^{-1} \mathrm{~s}^{-1}$, respectively. On the other hand, the average mobility for the $200{ }^{\circ} \mathrm{C}$-annealed $\mathbf{P} 3$ dropped slightly to $1.35 \mathrm{~cm}^{2} \mathrm{~V}^{-1} \mathrm{~s}^{-1}$. P4a having the same C20 side chains showed strikingly lower mobilities of 0.065 and $0.029 \mathrm{~cm}^{2} \mathrm{~V}^{-1} \mathrm{~s}^{-1}$ for the $150{ }^{\circ} \mathrm{C}$ - and $200{ }^{\circ} \mathrm{C}$-annealed thin films, respectively, which is most likely due to the very poor crystallinity (Fig. 4) and the poor intergranular connections (Fig. 6) of the polymer films. It was also noted that the mobilities of $\mathbf{P 4 b}\left(150{ }^{\circ} \mathrm{C}\right.$-annealed: $0.90 \mathrm{~cm}^{2} \mathrm{~V}^{-1}$ $\mathrm{s}^{-1}$; $200{ }^{\circ} \mathrm{C}$-annealed: $1.10 \mathrm{~cm}^{2} \mathrm{~V}^{-1} \mathrm{~s}^{-1}$ ) are much lower than those of P2b having the same $\mathrm{C} 24$ side chains $\left(150{ }^{\circ} \mathrm{C}\right.$-annealed: $2.65 \mathrm{~cm}^{2} \mathrm{~V}^{-1} \mathrm{~s}^{-1} ; 200{ }^{\circ} \mathrm{C}$-annealed: $1.46 \mathrm{~cm}^{2} \mathrm{~V}^{-1} \mathrm{~s}^{-1}$ ), which can also be attributed to the poorer crystallinity of $\mathbf{P 4 b}$. Some devices showed curved $I_{\mathrm{DS}}{ }^{1 / 2} v s$. $V_{\mathrm{GS}}$ lines (Fig. 4) and thus gatedependent mobilities (ESI $\dagger$ ). This bending phenomenon was also observed previously for PDQT ${ }^{25,34,35}$ and other high mobility polymers, ${ }^{27,29,42,43}$ which was explained by the carrier supersaturation in the conduction channel at high source/drain current regimes or low-density shallow charge trapping in the semiconductor and/or interface. ${ }^{27}$

Based on the above results, it appears that the presence of an appropriate amount of structural defects in the polymers synthesized by the Stille coupling polymerization could provide good solubility, increase molecular ordering, maintain short $\pi-\pi$ stacking distance, and improve film morphology. These characteristics favorably result in the enhanced charge transport performance of these polymers in OTFTs. The structurally regular polymers $\mathbf{P 4 a}$ and $\mathbf{P 4 b}$ showed very poor solution processability (poor solubility), low crystallinity, and poor morphology, leading to much lower charge carrier mobility in comparison to the "defected" polymers P1-P3.

\section{Conclusions}

We analyzed the structures of PDQT polymers synthesized using different polymerization methods and observed a correlation between the structure and the optoelectronic properties of these polymers. Our results confirmed the formation of the DBT-DBT and BT-BT structural defects due to the homocoupling side reactions of the $\mathrm{C}-\mathrm{Br}$ bonds and the organostannane species, respectively, during the Stille coupling polymerization in the presence of three different Pd catalysts. We found that $\mathrm{Pd}\left(\mathrm{PPh}_{3}\right)_{4}$ produced a PDQT polymer with fewest structural defects, while $\mathrm{Pd}\left(\mathrm{PPh}_{3}\right)_{2} \mathrm{Cl}_{2}$ gave the most irregular polymer backbone architecture. NMR measurements of the polymers at an elevated temperature of $125{ }^{\circ} \mathrm{C}$ revealed peaks representing the structural defects with an aid of the NMR spectra of the structurally well-defined polymers prepared by Yamamoto coupling with $\mathrm{Ni}(\mathrm{COD})_{2}$. MALDI-ToF mass spectroscopy further substantiated the presence of the DBT-DBT and BT-BT structural defects formed during the Stille coupling polymerization by detecting chains containing comonomer ratios not equal to the expected theoretical values. Isolation of a by-product from model Stille coupling reactions using these Pd catalyst systems validated that homocoupling involving the $\mathrm{C}-\mathrm{Br}$ bonds occurred to a significant extent during the Stille coupling reactions, which is responsible for the formation of the DBTDBT structural defects in the polymers. The existence of these structural defects was thought to result in the redshifts of the absorption profiles of the PDQT polymers. Surprisingly, the "perfect" structurally well-defined PDQT polymers prepared using Yamamoto coupling showed very poor molecular ordering in thin films presumably due to their rigid backbone that prevents the polymer chains from fine adjustment to form highly ordered molecular packing. As a result, these "perfect" 
polymers showed poor charge transport performance in OTFTs. On the contrary, polymers having significant amounts of structural defects prepared by the Stille coupling polymerization exhibited much improved molecular ordering and OTFT performance. Our results demonstrated that a "perfect" regular polymer may not lead to the best OTFT performance, while the existence of an appropriate/acceptable amount of structural defects in polymer chains can enhance the molecular ordering and thus the charge transport.

\section{Acknowledgements}

The authors thank the Natural Sciences and Engineering Research Council (NSERC) of Canada for financial support (Discovery Grants No. 402566-2011) of this work. S.C. thanks the Overseas Study Program of Guangzhou Elite Project provided by Guangzhou City, China. The authors would also like to thank Robin Sheppard of Xerox Corp. for performing the high temperature GPC analyses.

\section{Notes and references}

1 H. Klauk, Chem. Soc. Rev., 2010, 39, 2643-2666.

2 A. C. Arias, J. D. MacKenzie, I. McCulloch, J. Rivnay and A. Salleo, Chem. Rev., 2010, 110, 3-24.

3 A. Facchetti, Chem. Mater., 2010, 23, 733-758.

4 C. Wang, H. Dong, W. Hu, Y. Liu and D. Zhu, Chem. Rev., 2011, 112, 2208-2267.

5 H. Sirringhaus, P. J. Brown, R. H. Friend, M. M. Nielsen, K. Bechgaard, B. M. W. Langeveld-Voss, A. J. H. Spiering, R. A. J. Janssen, E. W. Meijer, P. Herwig and D. M. de Leeuw, Nature, 1999, 401, 685-688.

6 H. Sirringhaus, Adv. Mater., 2005, 17, 2411-2425.

7 B. S. Ong, Y. Wu, P. Liu and S. Gardner, J. Am. Chem. Soc., 2004, 126, 3378-3379.

8 I. McCulloch, M. Heeney, C. Bailey, K. Genevicius, I. MacDonald, M. Shkunov, D. Sparrowe, S. Tierney, R. Wagner, W. Zhang, M. L. Chabinyc, R. J. Kline, M. D. McGehee and M. F. Toney, Nat. Mater., 2006, 5, 328333.

9 B. S. Ong, Y. Wu, Y. Li, P. Liu and H. Pan, Chem.-Eur. J., 2008, 14, 4766-4778.

10 M. Zhang, H. N. Tsao, W. Pisula, C. Yang, A. K. Mishra and K. Müllen, J. Am. Chem. Soc., 2007, 129, 3472-3473.

11 J. Liu, R. Zhang, G. Sauvé, T. Kowalewski and R. D. McCullough, J. Am. Chem. Soc., 2008, 130, 1316713176.

12 H. Yan, Z. Chen, Y. Zheng, C. Newman, J. R. Quinn, F. Dotz, M. Kastler and A. Facchetti, Nature, 2009, 457, 679-686.

13 Y. Li, P. Sonar, S. P. Singh, W. Zeng and M. S. Soh, J. Mater. Chem., 2011, 21, 10829-10835.

14 X. Zhang, H. Bronstein, A. J. Kronemeijer, J. Smith, Y. Kim, R. J. Kline, L. J. Richter, T. D. Anthopoulos, H. Sirringhaus, K. Song, M. Heeney, W. Zhang, I. McCulloch and D. M. DeLongchamp, Nat. Commun., 2013, 4, 2238.
15 R. Noriega, J. Rivnay, K. Vandewal, F. P. V. Koch, N. Stingelin, P. Smith, M. F. Toney and A. Salleo, Nat. Mater., 2013, 12, 1038-1044.

16 D. Venkateshvaran, M. Nikolka, A. Sadhanala, V. Lemaur, M. Zelazny, M. Kepa, M. Hurhangee, A. J. Kronemeijer, V. Pecunia, I. Nasrallah, I. Romanov, K. Broch, I. McCulloch, D. Emin, Y. Olivier, J. Cornil, D. Beljonne and H. Sirringhaus, Nature, 2014, 515, 384-388.

17 A. Tsumura, H. Koezuka and T. Ando, Appl.Phys. Lett., 1986, 49, 1210-1212.

18 Z. Bao, A. Dodabalapur and A. J. Lovinger, Appl. Phys. Lett., 1996, 69, 4108-4110.

19 J. Li, K. H. Ong, P. Sonar, S. L. Lim, G. M. Ng, H. K. Wong, H. S. Tan and Z. K. Chen, Polym. Chem., 2013, 4, 804-811.

20 H. Li, F. Liu, X. Wang, C. Gu, P. Wang and H. Fu, Macromolecules, 2013, 46, 9211-9219.

21 I. Osaka, G. Sauvé, R. Zhang, T. Kowalewski and R. D. McCullough, Adv. Mater., 2007, 19, 4160-4165.

22 H. N. Tsao, D. Cho, J. W. Andreasen, A. Rouhanipour, D. W. Breiby, W. Pisula and K. Müllen, Adv. Mater., 2009, 21, 209-212.

23 Y. Li, S. P. Singh and P. Sonar, Adv. Mater., 2010, 22, 48624866.

24 C. Guo, W. Hong, H. Aziz and Y. Li, Reviews in Advanced Sciences and Engineering, 2012, 1, 200-224.

25 Y. Li, P. Sonar, L. Murphy and W. Hong, Energy Environ. Sci., 2013, 6, 1684-1710.

26 Y. He, W. Hong and Y. Li, J. Mater. Chem. C, 2014, 2, 86518661.

27 J. Li, Y. Zhao, H. S. Tan, Y. Guo, C.-A. Di, G. Yu, Y. Liu, M. Lin, S. H. Lim, Y. Zhou, H. Su and B. S. Ong, Sci. Rep., 2012, 2, 754.

28 I. Kang, H. J. Yun, D. S. Chung, S. K. Kwon and Y. H. Kim, J. Am. Chem. Soc., 2013, 135, 14896-14899.

29 C. Luo, A. K. K. Kyaw, L. A. Perez, S. Patel, M. Wang, B. Grimm, G. C. Bazan, E. J. Kramer and A. J. Heeger, Nano Lett., 2014, 14, 2764-2771.

30 G. Kim, S. J. Kang, G. K. Dutta, Y. K. Han, T. J. Shin, Y. Y. Noh and C. Yang, J. Am. Chem. Soc., 2014, 136, 9477-9483.

31 J. K. Stille, Angew. Chem., Int. Ed. Engl., 1986, 25, 508-524.

32 B. Carsten, F. He, H. J. Son, T. Xu and L. Yu, Chem. Rev., 2011, 111, 1493-1528.

33 Y. Li, P. Sonar, S. P. Singh, M. S. Soh, M. van Meurs and J. Tan, J. Am. Chem. Soc., 2011, 133, 2198-2204.

34 B. Sun, W. Hong, H. Aziz, N. M. Abukhdeir and Y. Li, J. Mater. Chem. C, 2013, 1, 4423.

35 S. Chen, B. Sun, W. Hong, H. Aziz, Y. Meng and Y. Li, J. Mater. Chem. C, 2014, 2, 2183-2190.

36 N. Miyaura and A. Suzuki, Chem. Rev., 1995, 95, 2457-2483.

37 K. H. Hendriks, W. Li, G. H. L. Heintges, G. W. P. van Pruissen, M. M. Wienk and R. A. J. Janssen, J. Am. Chem. Soc., 2014, 136, 11128-11133.

38 T. Yamamoto, A. Morita, Y. Miyazaki, T. Maruyama, H. Wakayama, Z. H. Zhou, Y. Nakamura, T. Kanbara, S. Sasaki and K. Kubota, Macromolecules, 1992, 25, 12141223. 
39 J. R. Matthews, W. Niu, A. Tandia, A. L. Wallace, J. Hu, W.-Y. Lee, G. Giri, S. C. B. Mannsfeld, Y. Xie, S. Cai, H. H. Fong, Z. Bao and M. He, Chem. Mater., 2013, 25, 782-789.

40 Y. Li, B. Sun, P. Sonar and S. P. Singh, Org. Electron., 2012, 13, 1606-1613.
41 V. Farina, V. Krishnamurthy, W. J. Scott and W. J. Scott, The Stille Reaction, Wiley, New York, 1998.

42 H. J. Chen, Y. L. Guo, G. Yu, Y. Zhao, J. Zhang, D. Gao, H. T. Liu and Y. Q. Liu, Adv. Mater., 2012, 24, 4618-4622.

43 J. Mei, D. H. Kim, A. L. Ayzner, M. F. Toney and Z. Bao, J. Am. Chem. Soc., 2011, 133, 20130-20133. 